5. Meyer KK, Beck WC. Gown-glove interface: a possible solution to the danger zone. Infect Control Hosp Epidemiol 1995;16: 488-490.

6. Fraser JF, Young SW, Valentine KA, Probst NE, Spangehl MJ. The gown-glove interface is a source of contamination: a comparative study. Clin Orthop Relat Res 2015;473:2291-2297.

7. Plut WJ, Ormond TH. Handware that improves protective apparel doffing. US Patent 7246382 2007:1-20.

\section{Clinical Guideline Inconsistency Regarding the Prevention of Hepatitis B and C Virus Transmission}

To the Editor-Every year, millions of people are infected with hepatitis $B$ virus (HBV) and hepatitis $\mathrm{C}$ virus (HCV). $\mathrm{HBV}$ and HCV share common modes of transmission. The exact route of transmission is unknown in a third of patients with acute $\mathrm{HBV}$ infections; similarly, 30\% of $\mathrm{HCV}$ patients do not have an identifiable risk factor. According to current $\mathrm{HBV}$ and $\mathrm{HCV}$ practice guidelines, including those from the United States Centers for Disease Control and Prevention, ${ }^{1,2}$ and the American Association for the Study of Liver Diseases, ${ }^{3,4}$ the sharing of toothbrushes is a risk factor for HBV and HCV transmission, but kissing is not. This seems to be a contradiction because it implies that indirect contact through the sharing of toothbrushes provides a more effective route of transmission than direct contact through kissing.

A toothbrush may induce gum bleeding, thereby facilitating oral infection. However, oral lesions and bleeding occur at any time and may be caused by traumas or multiple oral diseases (eg, ulcers, inflammation, cysts, oral tumors, jaw deformities, tooth impaction, etc.). These oral lesions and the associated bleeding may also facilitate $\mathrm{HBV}$ and $\mathrm{HCV}$ transmission during kissing.

A toothbrush is usually rinsed after use; therefore, it is relatively clean prior to its potential use by a second person. Further reduction in the number of available viral particles occurs when the potential second person rinse his/her mouth while tooth brushing. Thus, the amount of viral particles transferred should be at a trace level. In contrast, kissing directly transfers a greater amount of saliva between individuals. These facts do not support the current guidelines, which say that toothbrush sharing is a risk factor for HBV and HCV transmission but that kissing is not.

Investigations of infection routes have often focused on risk factors identified in practice guidelines, and patients also tend to associate their infections with risk factors they are aware of. These present blind spots in the study of risk factors. For example, sexual intercourse is considered a potential transmission route for $\mathrm{HBV}$ and $\mathrm{HCV} .{ }^{1-4}$ However, oral-oral kissing typically occurs simultaneously with sexual intercourse, confounding the analysis of whether the infection originated from genital sex, oral-genital sex, oraloral kissing, or a combination of these. Few studies have attempted to control for oral-oral infection during sexual intercourse. The density of $\mathrm{HBV}\left(10^{5-7}\right.$ virions $\left./ \mathrm{mL}\right)$ in saliva is actually similar to that in semen, ${ }^{5,6}$ and the density of $\mathrm{HCV}$ $\left(10^{6}\right.$ genome equivalents $\left./ \mathrm{mL}\right)$ in saliva is nearly $10 \%$ of that in serum. ${ }^{7}$ Furthermore, oral lesions are the most common form of lesions, and oral bleeding is the most common form of bleeding. Unfortunately, all these have been largely neglected.

Kissing directly transfers saliva and pathogens (if present) as does premastication. Reports have suggested that premastication may be associated with HBV transmission. For example, Huang reported that children fed by premastication had twice the prevalence of HBV infection. ${ }^{8}$

A study in Japan reported a case of acute $\mathrm{HBV}$ infection and suggested that this infection was caused by kissing. ${ }^{9}$ The patient had a steady partner infected with HBV and the sexual relationship between them only included deep kissing, with no sexual intercourse, oral-genital sex, or anal-genital sex, because the patient knew his partner was also infected with HIV. After the diagnosis of acute $\mathrm{HBV}$ infection, direct sequencing of the full HBV DNA genome indicated identical sequences in the patient and his partner.

A valid hypothesis that describes the transmission routes of a pathogen should be able to explain various epidemiological aspects of the diseases. We recently proposed that oral wounds can be a route of transmission for $\mathrm{HBV}$, and this hypothesis explains various observations regarding $\mathrm{HBV}$ epidemiology. ${ }^{10}$

Clinical practice guidelines play an important role in preventing the transmission of infectious diseases. Here, we present a striking inconsistency in the current $\mathrm{HBV}$ and $\mathrm{HCV}$ clinical practice guidelines regarding oral transmission. This inconsistency indicates that our understanding of HBV and $\mathrm{HCV}$ transmission is incomplete, especially with regard to the potential for oral transmission, and it suggests future directions for exploring potential risk factors.

\section{ACKNOWLEDGMENTS}

Financial support. No financial support was provided relevant to this article.

Potential conflicts of interest. Both authors report no conflicts of interest relevant to this article.

\section{Jianhua Lin, $\mathrm{MD}^{1}$ Jiman He, $\mathrm{PhD}^{1,2}$}

Affiliations: 1. Department of Gastroenterology, Nanfang Hospital, Southern Medical University, Guangzhou, China; 2. Liver Research Center, Rhode Island Hospital, Warren Alpert Medical School, Brown University, Providence, Rhode Island, United States. 
Address correspondence to Jiman He, Southern Medical University Nanfang Hospital, Guangzhou, 510515, China (jimanhe@smu.edu.cn or jiman_he@brown.edu).

Infect Control Hosp Epidemiol 2016;37:744-745

(C) 2016 by The Society for Healthcare Epidemiology of America. All rights reserved. 0899-823X/2016/3706-0028. DOI: 10.1017/ice.2016.50

\section{REFERENCES}

1. Viral Hepatitis-Hepatitis B Information. Centers for Disease Control and Prevention website. http://www.cdc.gov/hepatitis/ HBV/HBVfaq.htm. Accessed February 19, 2016.

2. Viral Hepatitis-Hepatitis C Information. Centers for Disease Control and Prevention website. http://www.cdc.gov/hepatitis/C/ cFAQ.htm. Accessed February 19, 2016.

3. Lok AS, McMahon BJ. Chronic hepatitis B. Hepatology 2007; 45:507-539.

4. Ghany MG, Strader DB, Thomas DL, et al. Diagnosis, management, and treatment of hepatitis C: an update. Hepatology 2009; 49:1335-74.

5. Jenison SA, Lemon SM, Baker LN, Newbold JE. Quantitative analysis of hepatitis B virus DNA in saliva and semen of chronically infected homosexual men. J Infect Dis 1987;156: 299-307.

6. Karayiannis P, Novick DM, Lok AS, Fowler MJ, Monjardino J, Thomas HC. Hepatitis B virus DNA in saliva, urine, and seminal fluid of carriers of hepatitis B e antigen. $\mathrm{Br}$ Med J (Clin Res Ed) 1985;290:1853-1855.

7. Rey D, Fritsch S, Schmitt C, Meyer P, Lang JM, Stoll-Keller F. Quantitation of hepatitis $\mathrm{C}$ virus RNA in saliva and serum of patients coinfected with $\mathrm{HCV}$ and human immunodeficiency virus. J Med Virol 2001;63:117-119.

8. Huang MJ. An epidemiological study on prevalence and risk factors of hepatitis B virus (HBV) infection in preschool children. Zhonghua Liu Xing Bing Xue Za Zhi 1990;11:129-132.

9. Kubo N, Furusyo N, Sawayama Y, et al. A patient in whom only hepatitis B virus (HBV) was thought to have been contracted, by kissing, from a same-sex partner coinfected with HBV and human immunodeficiency virus-1. J Infect Chemother 2003;9:260-264.

10. He J, Chen X, Sun J. Oral wounds and hepatitis B virus transmission. Infect Control Hosp Epidemiol 2014;35:1079-1080.

\section{Identification of Clostridium difficile RT078 From Patients and Environmental Surfaces in Zhejiang Province, China}

To the Editor-Clostridium difficile has been a predominant cause of nosocomial diarrhea in North America and Europe, especially after the emergence of PCR-ribotypes 027 and 078 . However, less emphasis is placed on the surveillance and control of $C$. difficile infection (CDI) in China. Li et al ${ }^{1}$ isolated a novel binary toxin strain of $C$. difficile from a hospitalized
TABLE 1. The Incidence of the Binary Toxin-Positive Strains of C. difficile in Three Tertiary Hospitals

\begin{tabular}{|c|c|c|c|c|}
\hline \multirow[b]{2}{*}{ Hospital } & \multicolumn{2}{|c|}{ Clinical Patients } & \multicolumn{2}{|c|}{ Environmental Surfaces } \\
\hline & $\begin{array}{l}\text { No. of } \\
\text { Isolates }\end{array}$ & $\begin{array}{l}\text { No. of Binary } \\
\text { Toxin-Positive } \\
\text { Strains }(\%)\end{array}$ & $\begin{array}{l}\text { No. of } \\
\text { Isolates }\end{array}$ & $\begin{array}{l}\text { No. of Binary } \\
\text { Toxin-Positive } \\
\text { Strains }(\%)\end{array}$ \\
\hline A & 33 & $0(0)$ & 2 & $0(0)$ \\
\hline B & 9 & $2(22)$ & 3 & $1(33)$ \\
\hline $\mathrm{C}$ & 19 & $2(11)$ & 32 & $3(9)$ \\
\hline Total & 61 & $4(7)$ & 37 & $4(11)$ \\
\hline
\end{tabular}

patient and mentioned that cases of ribotype 078 had not previously been reported in China. Here, we report 8 isolates that were identified as $C$. difficile ribotype 078 in a surveillance program in Zhejiang Province, China.

Our study was conducted at 3 tertiary hospitals (hospitals A, B, and C) from June 2013 to December 2014. A total of 98 unduplicated isolates of $C$. difficile from 61 clinical patients and 37 environmental surfaces were identified. A multiple polymerase chain reaction (multi-PCR) assay was used to amplify $16 \mathrm{~S}$ rDNA, $t c d \mathrm{~A}, t c d \mathrm{~B}, c d t \mathrm{~A}$, and $c d t \mathrm{~B}$ genes. The overall incidence of binary toxin-positive strains was $8.2 \%$; 4 isolates $(7 \%)$ were collected from patients, and $4(11 \%)$ isolates were collected from environmental surfaces (Table 1). In hospital B, $2(22 \%)$ of the detected binary toxin strains were obtained from patients and 1 strain (33\%) was isolated from an environmental surface. In hospital C, 2 strains (11\%) were identified from patients and 3 strains (9\%) were obtained from environmental surfaces. No hyper-toxigenic strain was detected in hospital A. According to the $t c d C$ gene sequence, all 8 isolates were identified as ribotype 078, with a mutation point at position 184 and a $\Delta 39$-bp deletion (Figure 1).

Previously, a few Asian countries and regions have reported the emergence of $C$. difficile ribotype 078, including Kuwait, ${ }^{2}$ South Korea, ${ }^{3}$ Iran, ${ }^{4}$ Japan, ${ }^{5}$ and Taiwan. ${ }^{6}$ The present study is the first to identify ribotype 078 cases not only from patients but also from environmental surfaces in China. Compared with neighboring Japan and Korea, the prevalence of CDI in China remains unclear, mainly due to a lack of awareness in the healthcare system. ${ }^{7}$ Many clinicians are accustomed to diagnosing patients with antibiotic-associated diarrhea by experience rather than by the results of stool cultures. In addition, although enzyme-linked immunosorbent assay (ELISA) has been used routinely to detect C. difficile in most tertiary hospitals in China, this method has a low sensitivity and does not trace the binary toxin strain. For these reasons, CDI, especially CDI caused by binary-toxin strains, may be severely underestimated in China.

China has the largest population with the trend of aging accompanied by antibiotic misuse, indicating the potential for epidemics of CDI. Medical practitioners should pay more attention to this global infection, as both $C$. difficile ribotypes 